\title{
Immune checkpoint inhibitor-induced myocarditis in cancer patients: a case report and review of reported cases
}

\author{
Emma Matzen ${ }^{1}$, Lars Erik Bartels², Brian Løgstrup ${ }^{3}$, Stine Horskær ${ }^{4}$, Christina Stilling ${ }^{4}$ and Frede Donskov ${ }^{*}$
}

\begin{abstract}
Background: Immune checkpoint inhibitor (ICI) induced myocarditis is a rare, severe, and often fatal adverse event. Evidence to guide appropriate immunosuppressive therapy is scarce. We present a case of ICl-induced myocarditis and a review of ICl-induced myocarditis cases to determine the most effective immunosuppressive therapeutic strategy for ICl-induced myocarditis.

Methods: A systematic search of PubMed was carried out for treatment of ICl-induced myocarditis. Reference lists from identified articles were manually reviewed for additional cases.

Results: A total of 87 cases with ICl-induced myocarditis were identified. The majority were melanoma $(n=39)$, lung cancer $(n=19)$, renal cell cancer $(n=10)$, and thymoma cancer patients $(n=4)$. In $38(44 \%)$ cases, patients received high-dose steroid treatment only. A total of $49(56 \%)$ cases were treated with immunosuppressive agents other than steroid; a total of 13 different immunosuppressive agents were used, including alemtuzumab or abatacept. The median time to onset of symptoms after initiation of ICI was 16 days (range, 1-196 days); cardiotoxic symptoms developed after 2 cycles of $\mathrm{ICI}$ (range, 1-13 cycles). A total of $48 \%$ of cases were fatal. In cases treated with high-dose steroids only vs. cases treated with other immunosuppressive agents, fatality was 55\% and 43\% respectively. In 64 out of the 87 cases, tumor control was not described. In patients treated with high-dose steroids only, two patients had stable disease as best tumor response; in patients treated with other immunosuppressive agents, one complete response, one partial response and seven stable disease were noted as best tumor response. Overall, 11 studies were at low risk of bias (12.6\%), 38 at moderate risk of bias (43.7\%) and 38 at high risk of bias (43.7\%).
\end{abstract}

Conclusion: Immune checkpoint inhibitor induced myocarditis is a serious and often fatal adverse event. High-dose prednisolone, alemtuzumab or abatacept are all possible treatments options for ICl-induced myocarditis, whereas infliximab increases the risk of death from cardiovascular causes, and should be avoided. Further research is needed.

Keywords: Checkpoint immunotherapy, Myocarditis, Immunosuppressive therapy

*Correspondence: fd@oncology.au.dk

1 Department of Oncology, Aarhus University Hospital, Palle Juul-Jensens, Boulevard 99, 8200 Aarhus N, Denmark

Full list of author information is available at the end of the article permits use, sharing, adaptation, distribution and reproduction in any medium or format, as long as you give appropriate credit to the original author(s) and the source, provide a link to the Creative Commons licence, and indicate if changes were made. The images or other third party material in this article are included in the article's Creative Commons licence, unless indicated otherwise in a credit line to the material. If material is not included in the article's Creative Commons licence and your intended use is not permitted by statutory regulation or exceeds the permitted use, you will need to obtain permission directly from the copyright holder. To view a copy of this licence, visit http://creativecommons.org/licenses/by/4.0/. The Creative Commons Public Domain Dedication waiver (http://creativeco $\mathrm{mmons}$.org/publicdomain/zero/1.0/) applies to the data made available in this article, unless otherwise stated in a credit line to the data. 


\section{Background}

Immune checkpoint inhibitor (ICI) therapy treatment has revolutionized the treatment of cancer. Checkpoint inhibitors are monoclonal antibodies targeting regulation receptors in the immune system such as programmed cell death receptor 1 (PD-1), programmed cell death ligand 1 (PD-L1), and cytotoxic T-lymphocyte-associated protein 4 (CTLA-4); binding to the inhibitory receptor mediates the immune system to attack and destroy cancer cells. ICI has shown activity in a large number of solid tumor and hematological malignancies, and is today the backbone therapy in many diseases [1].

ICI therapy may be associated with immune-related adverse events (irAE). A rare irAE is ICI-induced myocarditis, which is associated with a high mortality [2]. Mortality is most frequent in ICI combination therapy compared to ICI monotherapy [2].

There remains a lack of evidence to guide appropriate immunosuppressive therapy in ICI-induced myocarditis, as current guidelines are based on expert consensus; no randomized controlled studies have been performed to evaluate the efficiency of immunosuppressive therapeutic strategies. In the event of Common Toxicity Criteria for Adverse Events (CTCAE) of any grade, current guidelines recommend discontinuation ICI therapy and treatment with high-dose corticosteroids; if insufficient effect of steroid treatment, other immunosuppressive agents are suggested, such as antithymocyte globulin, mycophenolate mofetil, infliximab or tacrolimus [3]. Moreover, betablockers and angiotensin converting enzyme (ACE) inhibitors are indicated in patients with reduced LVEF according to heart failure guidelines [4]. However, the efficacy and safety of treatments for ICI-induced myocarditis have not been evaluated.

We present a case of ICI-induced myocarditis in a patient with metastatic renal cell carcinoma treated with checkpoint immunotherapy. Furthermore, we performed a systematic review of all known cases with ICI-induced myocarditis and reviewed the immunosuppressive treatments to identify the most effective strategy to attenuate toxicity while maintaining tumor control.

\section{Case presentation}

A 68-year-old man was diagnosed with synchronous metastatic renal cell carcinoma, with a primary tumor in the right kidney and metastases in the left adrenal gland, liver, lungs, pleurae and right chest wall. Blood tests showed anemia, elevated platelets, neutrophils, and corrected calcium; according to the International Metastatic Renal Cell Carcinoma Database Consortium (IMDC) [5] the patient was categorized in the poor risk prognostic group. The patient was treated with nivolumab (240 mg i.v.) and ipilimumab (88 $\mathrm{mg}$ i.v.). Twelve days after the second cycle of immunotherapy, the patient presented with dyspnea, peripheral edema, dizziness and chest pain, and was admitted to the emergency department. Biochemistry showed elevated cardiac biomarkers, TnI 5888 (ref. value $<24 \mathrm{ng} / \mathrm{l}$ ) (Fig. 1) and CK-MB 56.6 (ref. value $<7 \mu \mathrm{g} / \mathrm{l}$ ) and ALAT 309 (ref. value $<70 \mathrm{U} / \mathrm{l}$ ), suggestive of myocarditis and hepatitis. Electrocardiogram (ECG) showed a 3-degree atrio-ventricular block. A transthoracic echocardiogram (TTE) (cycle 2 day 12) showed slightly affected global longitudinal strain (GLS) of left ventricular function at $-17.5 \%$ (normal<-18.0\%), left ventricular ejection fraction (LVEF) was $50 \%$ (normal $>60 \%$ ), (Fig. $1 \mathrm{~A}$ ). Antibiotic treatment was started due to fever and elevated infection markers, CRP 43 (ref. value $<8 \mathrm{mg} / \mathrm{l}$ ) and leucocytes 16 (ref. value 3.5-10.0 10^9/1). Immunotherapy was discontinued. The patient started treatment the following day (cycle 2 day 13) with prednisolone $100 \mathrm{mg}$ daily. The patient was acutely transferred to a high facility Department of Cardiology at Aarhus University Hospital for a temporary pacemaker due to total atrioventricular block. A repeated TTE (cycle 2 day 14) showed clearly affected GLS of left ventricular function at $-14.0 \%$ (Fig. 1B); for comparison a TTE performed a year before admission showed normal GLS $-20.4 \%$ and EF $60 \%$ (Fig. 1C). Pulmonary embolism was excluded by an angio-CT of the thorax. Coronary angiography showed no significant findings. Due to the temporary pacemaker no cardiac MRI was performed. Endomyocardial biopsy obtained 3 days after presentation of symptoms (cycle 2 day 15) revealed severe myocyte necrosis with pronounced, patchy inflammation dominated by CD3-positive T-lymphocytes and occurrence of CD68-positive macrophages, consistent with the diagnosis of lymphocytic myocarditis (Fig. 2). Other causes of myocarditis (i.e., bacterial myocarditis, giant cell myocarditis, eosinophile myocarditis, CMV associated myocarditis and sarcoidosis) were excluded. Cardiac biomarkers kept declining on prednisolone treatment and sinus rhythm returned and treatment with the temporary pacemaker was terminated. A new TTE (cycle 2 day 21) showed improved cardiac function with a GLS of $-24.7 \%$ (Fig. 1D). The patient was discharged in his normal condition.

Twelve days later he was readmitted due to dyspnea. ECG showed atrial flutter and metoprolol $50 \mathrm{mg}$ daily and digoxin was initiated. Cardiac biomarkers were near normalized. The patient's clinical condition decreased, and due to infection, he started antibiotics. CT revealed progression of metastases in the lung, mediastinal lymph nodes and liver. The patient's condition continued to decline and he eventually expired, 

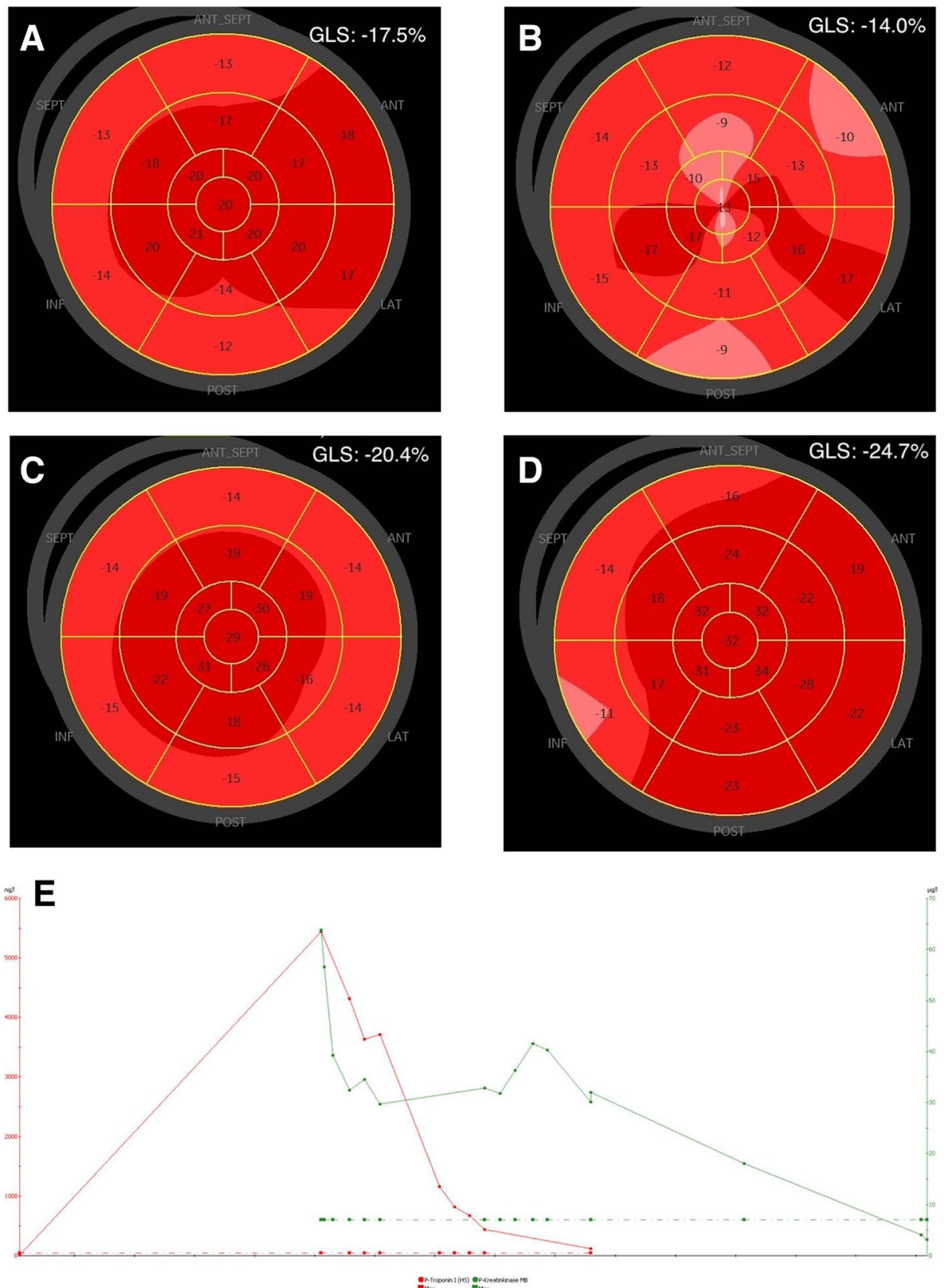

Fig. 1 Two-dimensional transthoracic echocardiography (TTE) with global longitudinal strain (A-D) analysis and cardiac biomarkers (E). A TTE performed at the day of admission at the department of cardiology, at debut of symptoms, (cycle 2 day 12). B TTE performed on the day of peak of cardiac biomarkers, (cycle 2 day 14). C TTE performed approximately 1 year before admission. DTTE performed at the day of discharge, (cycle 2 day 21). E Cardiac biomarkers showing troponin peak. Troponin and CK-MB declined after initiation of high-dose steroid

approximately 8 and a half weeks after the second dose of immunotherapy.

\section{Methods}

\section{Information and search strategy}

A systematic search in the medical database PubMed was conducted using the terms "checkpoint immunotherapy" and "checkpoint inhibitor immunotherapy-associated myocarditis" and "treatment". The search included $1^{\text {st }}$ of January 2000 to the $22^{\text {nd }}$ of January 2021. Reference lists from identified articles were manually reviewed for additional cases.

\section{Eligibility criteria}

A literature search involving studies of patients with ICIinduced myocarditis treated with immunosuppressive 


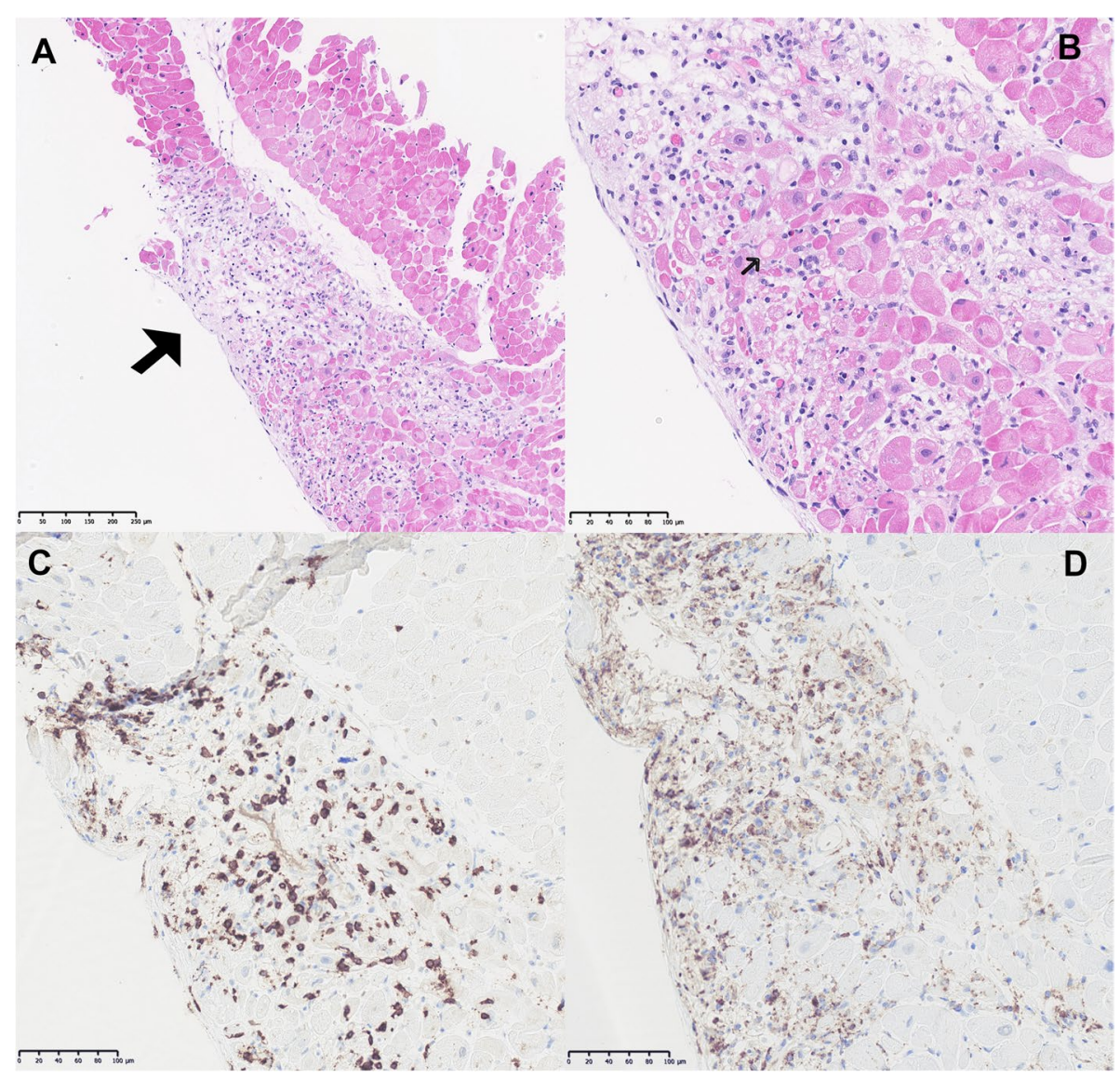

Fig. 2 Pathological characteristics of immune checkpoint inhibitor-induced myocarditis. A Hematoxylin and eosin stain of patchy inflamed myocardium $\times 10$ (arrow). B Hematoxylin and eosin stain of inflamed myocardium with necrotic myocytes $\times 20$ (arrow). C CD3-positive T-lymphocytes, immunohistochemical staining $\times 20$. D CD68-positive macrophages, immunohistochemical staining $\times 20$

agents was conducted to answer the predefined PICO question:

Is it possible to improve the treatment of ICIinduced myocarditis by integrating an immunosuppressive agent as an alternative or supplement to prednisolone?

a. Population - Cancer patients treated with checkpoint inhibitors (PD-1-, PD-L1- or CTLA-4-inhibitor) and adverse event with myocarditis.

b. Intervention - Immunosuppressive therapy other than steroid, added to steroid-treatment - either mono or combination therapy.

c. Comparators - steroid mono therapy vs. other immunosuppressive therapy.

d. Outcome(s) - Primary outcome: death. Secondary outcome: sustained cardiac function. Third outcome: maintained tumor control.

\section{Study selection}

The screening program Covidence was used to screen articles based on title and abstract to identify potential studies. Articles for full-text screening were retrieved online and evaluated for eligibility.

\section{Risk of bias (methodological quality) assessment of included studies}

Risk of bias (methodological quality) was assessed using a tool developed by Murad et al. [6], to evaluate the methodological quality/risk of bias of case reports and case series based on the following domains: selection, ascertainment, causality and reporting. The domains contain a total of 8 questions; we removed the $5^{\text {th }}$ question concerning challenge/re-challenge phenomena, as the included cases did not describe any challenge/rechallenge phenomena, rendering 7 questions to address in this analysis. The questions were answered with a 
Table 1 Risk of bias assessment of included studies

\begin{tabular}{|c|c|c|c|c|c|c|c|c|c|c|c|c|c|c|c|}
\hline \multirow[t]{2}{*}{ First author } & \multicolumn{2}{|c|}{ Q 1} & \multicolumn{2}{|c|}{ Q 2} & \multicolumn{2}{|c|}{ Q 3} & \multicolumn{2}{|c|}{ Q 4} & \multicolumn{2}{|c|}{ Q 6} & \multicolumn{2}{|c|}{ Q 7} & \multicolumn{2}{|c|}{ Q 8} & \multirow[t]{2}{*}{ Risk of bias } \\
\hline & $\mathrm{Y}$ & $\mathbf{N}$ & $\mathbf{Y}$ & $\mathrm{N}$ & $Y$ & $\mathrm{~N}$ & $\mathrm{Y}$ & $\mathrm{N}$ & $\mathrm{Y}$ & $\mathbf{N}$ & $\mathrm{Y}$ & $\mathrm{N}$ & $Y$ & $\mathrm{~N}$ & \\
\hline Doms [7] & & $x$ & $x$ & & $x$ & & $x$ & & $x$ & & $x$ & & $x$ & & Moderate \\
\hline Esfahani [8] & & $x$ & $x$ & & $x$ & & $x$ & & $x$ & & $x$ & & $\mathrm{X}$ & & Moderate \\
\hline Salem [9] & & $x$ & $x$ & & $x$ & & $x$ & & $x$ & & $x$ & & $\mathrm{X}$ & & Moderate \\
\hline Matzen [10] & $x$ & & $x$ & & $x$ & & $x$ & & $x$ & & $x$ & & $\mathrm{X}$ & & Low \\
\hline Läubli [11] & & $x$ & $x$ & & $x$ & & $x$ & & $x$ & & $x$ & & $x$ & & Moderate \\
\hline Zimmer [12] & $x$ & & $x$ & & $x$ & & & $x$ & $x$ & & $x$ & & $x$ & & Moderate \\
\hline Behling [13] & & $x$ & $\mathrm{x}$ & & $x$ & & $x$ & & $x$ & & $x$ & & $\mathrm{X}$ & & Moderate \\
\hline Semper [14] & $x$ & & $x$ & & $x$ & & $x$ & & $x$ & & $x$ & & $x$ & & Low \\
\hline Mahmood [15] & & $x$ & $x$ & & $x$ & & $x$ & & $x$ & & $x$ & & & $x$ & High \\
\hline Jain [16] & & $x$ & $x$ & & $x$ & & & $x$ & $x$ & & $x$ & & $\mathrm{X}$ & & High \\
\hline Liu [17] & & $x$ & $x$ & & $x$ & & $x$ & & $x$ & & $x$ & & $\mathrm{X}$ & & Moderate \\
\hline Frigeri [18] & & $x$ & $x$ & & $x$ & & $x$ & & $x$ & & $x$ & & $x$ & & Moderate \\
\hline Norwood [19] & & $x$ & $x$ & & $x$ & & $x$ & & $x$ & & $x$ & & $x$ & & Moderate \\
\hline Arangalage [20] & & $x$ & $x$ & & $x$ & & $x$ & $x$ & $x$ & & $x$ & & & $x$ & High \\
\hline Yogasundaram [21] & & $x$ & $x$ & & $x$ & & $x$ & & $\mathrm{x}$ & & $x$ & & $\mathrm{X}$ & & Moderate \\
\hline Tay [22] & & $x$ & $x$ & & $x$ & & $x$ & & $\mathrm{x}$ & & $x$ & & $\mathrm{X}$ & & Moderate \\
\hline Tadokoro [23] & & $x$ & $x$ & & $x$ & & $x$ & & $\mathrm{x}$ & & $x$ & & $\mathrm{x}$ & & Moderate \\
\hline Gibson [24] & & $x$ & $x$ & & $x$ & & $x$ & & $x$ & & $x$ & & $\mathrm{X}$ & & Moderate \\
\hline Guiney [25] & & $x$ & $x$ & & $x$ & & & $x$ & $x$ & & $x$ & & $x$ & & High \\
\hline Osnat [26] & & $x$ & $x$ & & $x$ & & $x$ & & $x$ & & $x$ & & $x$ & & Moderate \\
\hline Mehta [27] & & $x$ & $x$ & & $x$ & & $x$ & & $\mathrm{x}$ & & $x$ & & $\mathrm{X}$ & & Moderate \\
\hline Reuben [28] & & $x$ & $x$ & & $x$ & & $x$ & & $x$ & & $x$ & & & $x$ & High \\
\hline Tajmir-Riahi [29] & & $x$ & $x$ & & $x$ & & $x$ & & $\mathrm{x}$ & & $x$ & & $\mathrm{X}$ & & Moderate \\
\hline Berg [30] & & $x$ & $x$ & & $x$ & & $x$ & & $\mathrm{x}$ & & $x$ & & $\mathrm{X}$ & & Moderate \\
\hline Samara [31] & & $x$ & $x$ & & $x$ & & & $x$ & $x$ & & $x$ & & $x$ & & High \\
\hline Khoury [32] & & $x$ & $x$ & & $x$ & & & $x$ & $x$ & & $x$ & & $\mathrm{X}$ & & High \\
\hline Katsume [33] & & $x$ & $x$ & & $x$ & & $x$ & & $x$ & & $x$ & & $x$ & & Moderate \\
\hline Yanase [34] & & $x$ & $x$ & & $x$ & & $x$ & & $x$ & & $x$ & & $x$ & & Moderate \\
\hline Reddy [35] & & $x$ & $x$ & & $x$ & & $x$ & & $x$ & & $x$ & & & $x$ & High \\
\hline Ganatra [36] & & $x$ & $x$ & & $x$ & & $x$ & & $x$ & & $x$ & & $\mathrm{X}$ & & Moderate \\
\hline Fukusawa [37] & & $x$ & $x$ & & $x$ & & $x$ & & $\mathrm{x}$ & & $x$ & & $\mathrm{x}$ & & Moderate \\
\hline Heinzerling [71] Case 1,5 \& 8 & $x$ & & $x$ & & $x$ & & $x$ & & $\mathrm{x}$ & & $x$ & & $\mathrm{x}$ & & Low \\
\hline Imai [38] & & $x$ & $x$ & & $x$ & & $x$ & & $\mathrm{x}$ & & $x$ & & & $\mathrm{x}$ & High \\
\hline Johnson [39] Case 1 \& 2 & & $x$ & $x$ & & $x$ & & & $x$ & $x$ & & $x$ & & $x$ & & High \\
\hline Nasr [40] & & $x$ & $x$ & & $x$ & & $x$ & & $\mathrm{x}$ & & $x$ & & $\mathrm{X}$ & & Moderate \\
\hline Rota [41] Case $1 \& 2$ & & $x$ & $\mathrm{X}$ & & $x$ & & $x$ & & $\mathrm{x}$ & & $x$ & & $\mathrm{x}$ & & Moderate \\
\hline Yamaguchi [42] & & $x$ & $\mathrm{x}$ & & $x$ & & $x$ & & $x$ & & $\mathrm{x}$ & & $\mathrm{X}$ & & Moderate \\
\hline Chen [43] & & $x$ & $\mathrm{x}$ & & $x$ & & $x$ & & $x$ & & $\mathrm{x}$ & & $\mathrm{x}$ & & Moderate \\
\hline Nierstedt [44] & & $x$ & $x$ & & $x$ & & $x$ & & $x$ & & $x$ & & & $x$ & High \\
\hline Christina [45] & & $x$ & $x$ & & $x$ & & & & $x$ & & $x$ & & $\mathrm{x}$ & & High \\
\hline Copeland-Halperin [46] & & $x$ & $\mathrm{x}$ & & $x$ & & $x$ & & $\mathrm{x}$ & & $x$ & & & $\mathrm{x}$ & High \\
\hline Gallegos [47] & & $x$ & $\mathrm{x}$ & & $x$ & & & $\mathrm{x}$ & $\mathrm{x}$ & & $\mathrm{x}$ & & $\mathrm{X}$ & & High \\
\hline Inayat [48] & & $x$ & $\mathrm{x}$ & & $x$ & & $x$ & & $\mathrm{x}$ & & $\mathrm{x}$ & & & & Moderate \\
\hline Lopez [49] Case 1 & & $x$ & $x$ & & $x$ & & $x$ & & $x$ & & $\mathrm{x}$ & & & $x$ & High \\
\hline Lopez [49] Case 2 & & $x$ & $x$ & & $x$ & & & $\mathrm{x}$ & $x$ & & $x$ & & & $\mathrm{x}$ & High \\
\hline Martinez-Calle [50] & & $x$ & $x$ & & $x$ & & $x$ & & $x$ & & $x$ & & $x$ & & Moderate \\
\hline Monge [51] & & $x$ & $x$ & & $x$ & & & $\mathrm{x}$ & $x$ & & $x$ & & $\mathrm{x}$ & & High \\
\hline Sakai [52] & & $x$ & $x$ & & $x$ & & $x$ & & $x$ & & $x$ & & & $x$ & High \\
\hline
\end{tabular}


Table 1 (continued)

\begin{tabular}{|c|c|c|c|c|c|c|c|c|c|c|c|c|c|c|c|}
\hline \multirow[t]{2}{*}{ First author } & \multicolumn{2}{|c|}{ Q 1} & \multicolumn{2}{|c|}{ Q 2} & \multicolumn{2}{|c|}{ Q 3} & \multicolumn{2}{|c|}{ Q 4} & \multicolumn{2}{|c|}{ Q 6} & \multicolumn{2}{|c|}{ Q 7 } & \multicolumn{2}{|l|}{ Q 8} & \multirow[t]{2}{*}{ Risk of bias } \\
\hline & $\mathrm{Y}$ & $\mathbf{N}$ & $\mathrm{Y}$ & $\mathbf{N}$ & $\mathrm{Y}$ & $\mathbf{N}$ & $\mathrm{Y}$ & $\mathbf{N}$ & $\mathrm{Y}$ & $\mathbf{N}$ & $\mathrm{Y}$ & $\mathbf{N}$ & $\mathbf{Y}$ & $\mathbf{N}$ & \\
\hline Balanescru [53] Case 1 & $\mathrm{x}$ & & $\mathrm{x}$ & & $\mathrm{x}$ & & $\mathrm{x}$ & & $\mathrm{x}$ & & $\mathrm{x}$ & & $x$ & & Low \\
\hline Balanescru [53] Case $2 \& 3$ & $\mathrm{x}$ & & $\mathrm{x}$ & & $\mathrm{x}$ & & $\mathrm{x}$ & & $\mathrm{x}$ & & $\mathrm{x}$ & & & $\mathrm{x}$ & Moderate \\
\hline Guo [54] Case $1 \& 3$ & $x$ & & $x$ & & $x$ & & $\mathrm{x}$ & & $\mathrm{x}$ & & $x$ & & $\mathrm{x}$ & & Low \\
\hline Guo [54] Case 2 \& 5 & $\mathrm{x}$ & & $x$ & & $x$ & & & $\mathrm{x}$ & $\mathrm{x}$ & & $\mathrm{x}$ & & $\mathrm{x}$ & & Moderate \\
\hline Bukamur [55] & & $x$ & $x$ & & $x$ & & & $x$ & $x$ & & $x$ & & & $x$ & High \\
\hline Agrawal [56] Case 1,2 \& 3 & $x$ & & $x$ & & $x$ & & $x$ & & $\mathrm{x}$ & & $\mathrm{x}$ & & $\mathrm{x}$ & & Low \\
\hline Agrawal [56] Case 4 & $\mathrm{x}$ & & $\mathrm{x}$ & & $x$ & & & $x$ & $x$ & & $x$ & & & $x$ & High \\
\hline Agrawal [56] Case 5 & $\mathrm{x}$ & & $\mathrm{x}$ & & $\mathrm{x}$ & & $\mathrm{x}$ & & $x$ & & $x$ & & & $x$ & Moderate \\
\hline Arora [57] Case 1,2,3,7 & & $\mathrm{x}$ & $\mathrm{x}$ & & $\mathrm{x}$ & & & $\mathrm{x}$ & $\mathrm{x}$ & & $\mathrm{x}$ & & & $\mathrm{x}$ & High \\
\hline Arora [57] Case 4 & & $\mathrm{x}$ & $x$ & & $x$ & & $\mathrm{x}$ & & $\mathrm{x}$ & & $\mathrm{x}$ & & & $x$ & High \\
\hline Arora [57] Case 8 & & $\mathrm{x}$ & $x$ & & $x$ & & & $\mathrm{x}$ & $x$ & & $x$ & & $x$ & & High \\
\hline Xing [58] & & $x$ & $x$ & & $x$ & & & $x$ & $x$ & & $x$ & & $\mathrm{x}$ & & High \\
\hline Kimura [59] & & $x$ & $x$ & & $x$ & & $x$ & & $x$ & & $x$ & & $x$ & & Moderate \\
\hline Fazel [60] & & $x$ & $x$ & & $x$ & & & $\mathrm{x}$ & $x$ & & $x$ & & $x$ & & High \\
\hline Hardy [61] & & $\mathrm{x}$ & $\mathrm{x}$ & & $x$ & & $x$ & & $x$ & & $x$ & & $\mathrm{x}$ & & Moderate \\
\hline Saibil [62] & & $\mathrm{x}$ & $\mathrm{x}$ & & $\mathrm{x}$ & & $x$ & & $x$ & & $x$ & & & $x$ & High \\
\hline Ansari-Gilani [63]Case 1\&2 & & $\mathrm{x}$ & $\mathrm{x}$ & & $\mathrm{x}$ & & $\mathrm{x}$ & & $\mathrm{x}$ & & $\mathrm{x}$ & & $\mathrm{x}$ & & Moderate \\
\hline Ansari-Gilani [63] Case 3 & & $\mathrm{x}$ & $x$ & & $x$ & & & $\mathrm{x}$ & $\mathrm{x}$ & & $\mathrm{x}$ & & $\mathrm{x}$ & & High \\
\hline McDowall [64] & & $\mathrm{x}$ & $x$ & & $x$ & & $x$ & & $\mathrm{x}$ & & $x$ & & $\mathrm{x}$ & & Moderate \\
\hline Shah [65] & $x$ & & $x$ & & $x$ & & & $\mathrm{x}$ & $x$ & & $\mathrm{x}$ & & & $x$ & High \\
\hline Joseph [66] & $x$ & & $\mathrm{x}$ & & $\mathrm{x}$ & & & $\mathrm{x}$ & $\mathrm{x}$ & & $\mathrm{x}$ & & & $x$ & High \\
\hline Zhang [67] & $\mathrm{x}$ & & $x$ & & $x$ & & & $x$ & $x$ & & $x$ & & & $x$ & High \\
\hline Konstantina [68] Case 1 & & $\mathrm{x}$ & $\mathrm{x}$ & & $x$ & & $x$ & & $\mathrm{x}$ & & $x$ & & & $x$ & High \\
\hline Konstantina [68] Case 2 & & $\mathrm{x}$ & $\mathrm{x}$ & & $\mathrm{x}$ & & $x$ & & $\mathrm{x}$ & & $\mathrm{x}$ & & & $\mathrm{x}$ & High \\
\hline Wang [69] & & $\mathrm{x}$ & $x$ & & $x$ & & & $\mathrm{x}$ & $\mathrm{x}$ & & $\mathrm{x}$ & & $\mathrm{x}$ & & High \\
\hline von Itzstein [70] & & $\mathrm{x}$ & $x$ & & $x$ & & & $x$ & $x$ & & $\mathrm{x}$ & & $x$ & & High \\
\hline $\begin{array}{l}\text { Total: } \\
87 \text { cases }\end{array}$ & 20 & 67 & 67 & & 67 & & 59 & 29 & 87 & & 87 & & 62 & 25 & $\begin{array}{l}\text { Low risk: } 11 \\
\text { Moderate risk: } 38 \\
\text { Moderate risk: } 38\end{array}$ \\
\hline
\end{tabular}

Y:yes, N: no, Q: question

Question 1: Does the patient(s) represent(s) the whole experience of the investigator (centre) or is the selection method unclear to the extent that other patients with similar presentation may not have been reported?

Question 2: Was the exposure adequately ascertained?

Question 3: Was the outcome adequately ascertained?

Question 4: Were other alternative causes that may explain the observation ruled out?

Question 5: Was there a challenge/re-challenge phenomenon?

Question 6: Was there a dose-response effect?

Question 7: Was follow-up long enough for outcomes to occur?

Question 8: Is the case(s) described with sufficient details to allow other investigators to replicate the research or to allow practitioners make inferences related to their own practice?

binary response to indicate whether the report was suggestive of bias or not. The quality of the report was considered good (low risk of bias), when all 7 criteria were fulfilled, moderate when 6 were fulfilled and poor when 5 or less were fulfilled (Table 1). First author assessed the risk of bias of the included studies.

\section{Results}

\section{Study characteristics}

The flow diagram of the study selection is shown in Fig. 3. The literature search resulted in the retrieving of 73 publications. Sixty-six articles were added during manual search of the bibliographies of identified articles. Of the 


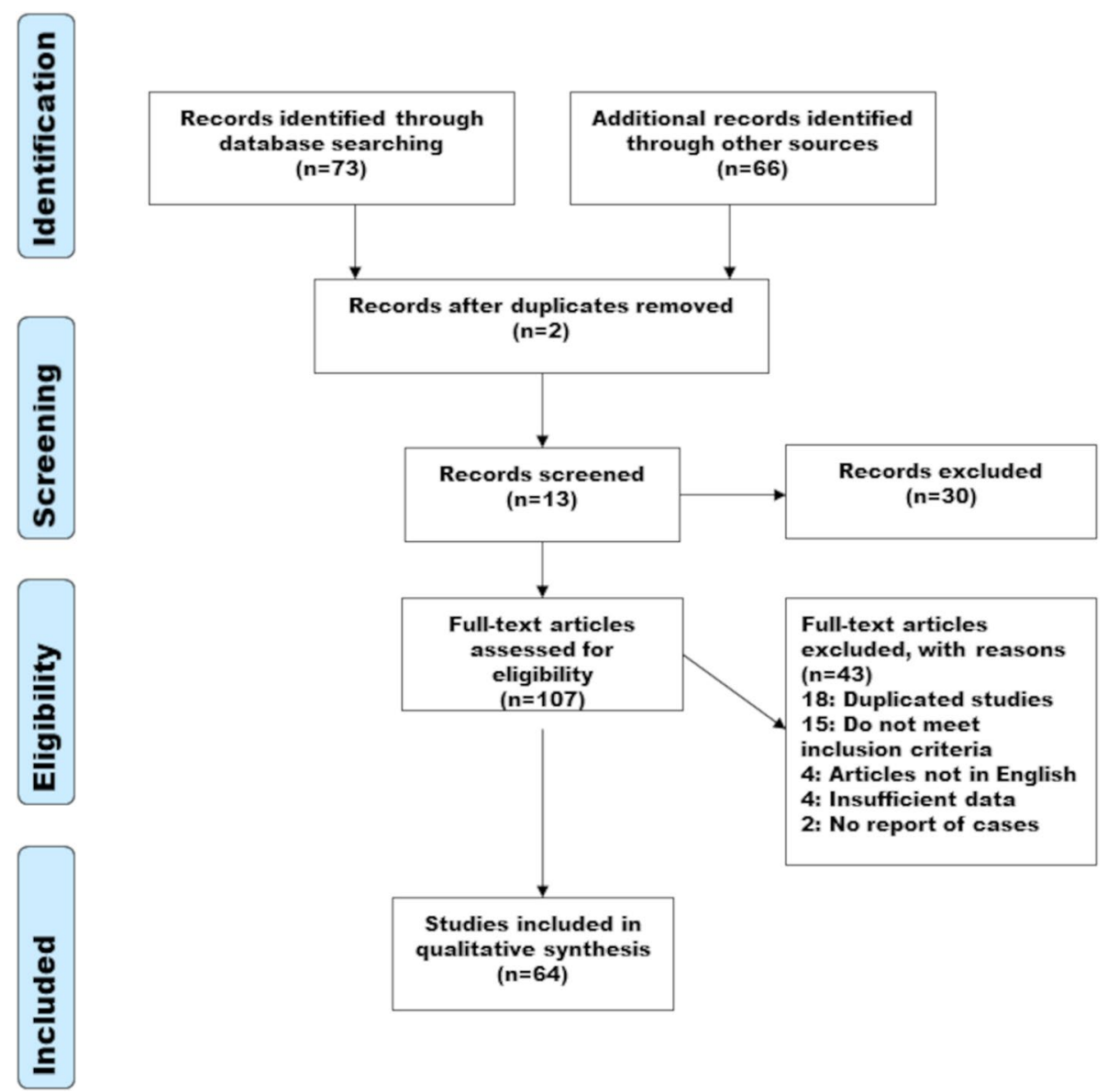

Fig. 3 PRISMA flow diagram: The selection process including exclusion criteria

139 articles, 2 were duplicates, leaving 137 articles for screening. One hundred seven publications were potentially eligible after title- and abstract screening. Full text screening was made on 107 articles and 43 articles were excluded for the following reasons: Fifteen publications did not meet inclusion criteria, 4 articles were not written in English, 2 articles did not contain any report of cases, 4 articles contained insufficient data in the case reports and finally, 18 studies were duplicated. A total 66 articles containing case reports were included in the qualitative synthesis. The publication date of the included studies ranged from 2015 to 2021.

\section{Risk of bias assessment}

The results of risk of bias assessment of included studies are shown in Table 1.

Eleven studies were at low risk of bias (12.6\%), 38 at moderate risk of bias (43.7\%) and 38 at high risk of bias (43.7\%). For question 1 (Table 1), 67 studies contained an unclear selection approach, as they did not mention whether the reported patient(s) represented the whole experience of the medical center and therefore had reported all known cases in their center. There could be a risk that patients with a similar presentation may not have been reported, as one could expect that mild asymptomatic cases with only biochemical evidence suggestive of myocarditis could be overlooked. The same could be mentioned in regards to serious cases of ICI-induced myocarditis, which may not have been reported for different reasons. Both could lead to selection bias.

For question 4, 29 studies did not describe whether alternative causes (e.g., viruses, other drugs or acute myocardial infarction etc.) that could give rise to similar symptoms were ruled out. For the domain of reporting (question 8) 25 studies did not describe the intervention with immunosuppressive agents with sufficient details (precise dosage of one or more of the immunosuppressive agents were not mentioned), which makes it difficult for readers to apply the evidence derived from the report in their practice. 


\section{Patient characteristics}

A total of 87 patient cases were included. All patients had a cancer diagnosis and were treated with ICIs (anti-PD-1, anti-PD-L1 and anti-CTLA-4-inhibitor) mono or combination therapy. Thirty-nine patients were diagnosed with melanoma, 19 with lung cancer, 10 with renal cell carcinoma, 2 with prostate cancer, 4 with thymic carcinoma, 2 with urothelial carcinoma, 1 with endometrial cancer, 1 with glioblastoma, 1 with chronic myelomonocytic leukemia, 1 with metastatic sarcoma, 1 with metastatic breast cancer, 1 with metastatic gastric carcinoma, 1 with esophageal adenocarcinoma, 1 with myeloma and 1 with mesothelioma. Two patients were diagnosed with myelodysplastic syndrome (MDS), which is characterized as a pre-leukemic disease [53]. Other adverse events than myocarditis induced by ICI therapy reported in the studies were hepatitis (15 patients), myositis (24 patients), colitis (2 patients), thyroiditis (11 patients), myasthenia gravis (13 patients), pneumonitis (2 patients), rhabdomyolysis (2 patients), hypophysitis (3 patients), neuritis (1 patient), polyneuropathy (1 patient), conjunctivitis/uveitis (1 patient), Syndrome of inappropriate antidiuretic hormone (1 patient), encephalitis (1 patient) and Stevens-Johnson syndrome (1 patient). Adverse events due to the immunosuppressive regimens were not reported in any of the included studies.

The diagnosis of myocarditis was based on cardiac biomarkers, ECG, echocardiography, cardiac magnetic resonance or computer tomography of the heart, cardiac catherization and endomyocardial biopsy. Twenty studies included biopsy-verified myocarditis with findings of immune infiltration of the myocardium with CD4positive T-lymphocytes, CD8-positive T-lymphocytes and CD68-positive macrophages $[11,16,19,22,23,26$, $36-39,42,43,47,50,61,62,67,71]$. One study included several biopsies performed during and after immunosuppressive therapy showing improvement with evidence of early repair, less inflammatory cells and patchy foci of fibrosis [22].

\section{Immunosuppressive treatment}

Reported immunosuppressive regimens in the included studies consisted of high-dose glucocorticoids, antithymocyte globulin (ATG), mycophenolate mofetil, alemtuzumab, infliximab, abatacept, plasmapheresis, tocilizumab, immunoglobulin, rituximab, tacrolimus, methotrexate and cyclophosphamide. In 38 (44\%) cases, the patients received high-dose steroid treatment only. The immunosuppressive regimens of the 49 (56\%) cases consisted of treatment with one or more immunosuppressive agents other than steroids (Table 2). Effects of the immunosuppressive regimens were measured on improvement in clinical condition, cardiac biomarkers and LVEF.

\section{Outcomes}

The median time to onset of symptoms after initiation of ICI was 16 days, but with a wide variation of 1 to 196 days. Number of ICI-cycles was described in 63 of the cases. In average cardiotoxic symptoms developed after 2 cycles of ICI with a variation of 1 to 13 cycles. Fatal outcome was observed in $48 \%$ of the cases. Death was caused by cardiac complications, infections or clinical deterioration. Follow-up in the cases had a wide variation as some cases did not have any follow-up after the patients were discharged and others included a follow-up after several months.

Twenty-one of the 38 patients (55\%), treated with highdose steroids only, died. Five patients died of sudden cardiac arrest, 3 patients expired due to arrhythmia, 1 patient died due to infection and 12 patients experienced clinical deterioration and were transitioned to comfort care. The remaining 17 patients out of the 38 (45\%) showed improvement in clinical condition. Seven patients had improved LVEF and 3 patients had improved biochemical markers (declining cardiac biomarkers). Of the 49 cases treated with one or more immunosuppressive agents other than steroid, 21 (43\%) were fatal. Twenty-eight out of the 49 patients (57\%) showed improved clinical condition with immunosuppressive treatment. Six patients had improvement in cardiac biomarkers with declining/normalized troponin levels, 4 patients had improvement in ECG and 8 patients showed improved LVEF. Comparing fatality in the cases, $55 \%$ treated with high-dose steroids only were fatal vs. $43 \%$ fatality in cases treated with other immunosuppressive agents.

The immunosuppressive therapy regimens in the cases treated with immunosuppressive agents other than steroid (23 out of 49 ) varied, as only 3 cases were not treated with steroid initially, but with only one immunosuppressive agent being either ATG (1 patient) [67] or immunoglobulin (3 patients) [53]. The other 20 cases were treated with steroid initially, followed by one to four other immunosuppressive agents due to lack of improvement in clinical condition, cardiac biomarkers, ECG or LVEF [7-9, 15, 17-20, 22, 26, 34, 35, 41, 42, 54, $56,58,69,70]$.

In 64 out of the 87 cases, tumor control was not described. In the patients treated with high-dose steroids only, two patients had stable disease [23, 59] and seven patients showed progression of metastatic disease $[10,13,54,63,71]$. In the cases treated with one or more immunosuppressive agents other than steroid, complete tumor response was reported in one patient [8] and partial tumor response was reported in one patient [34]. 


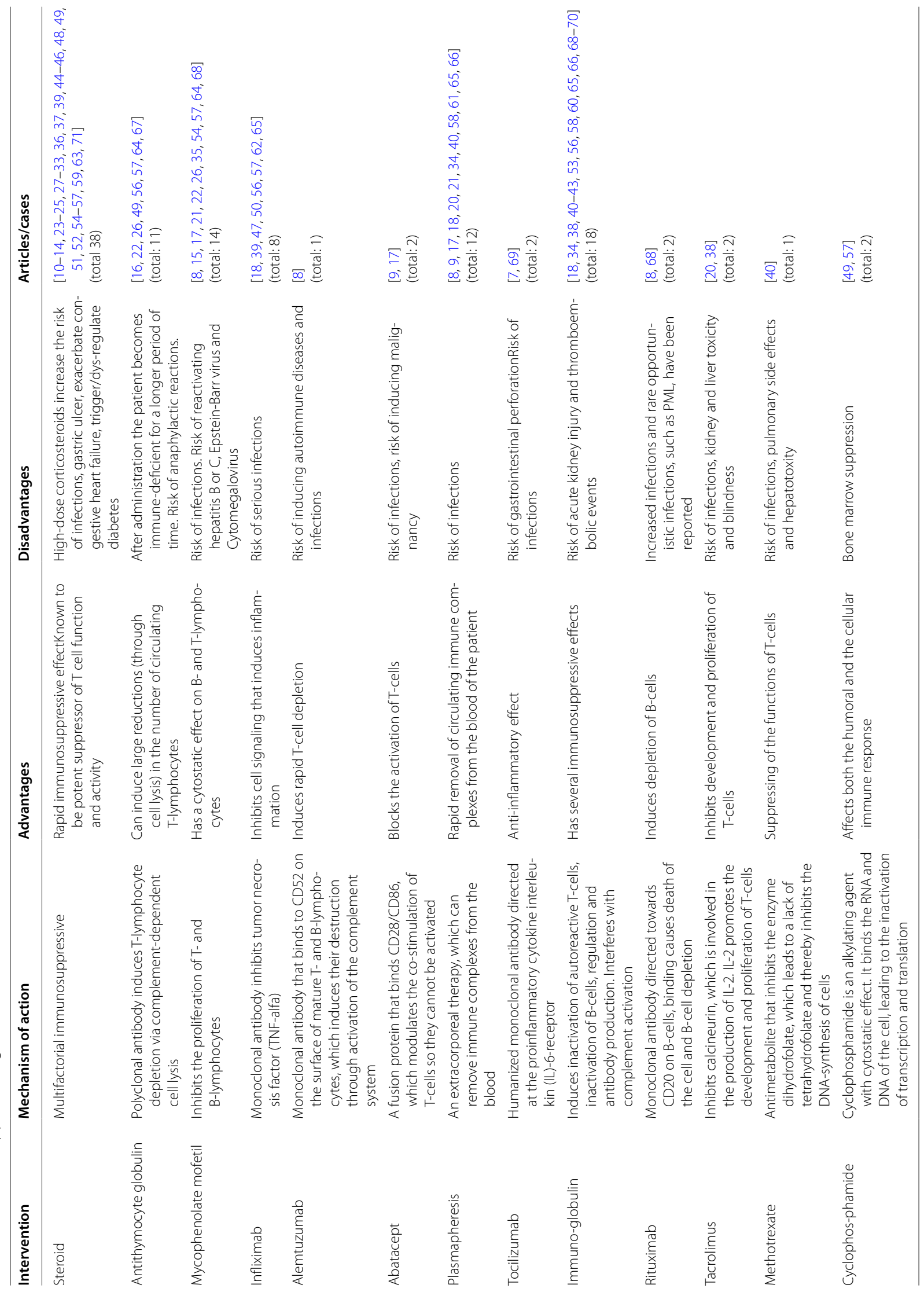


Stable disease was reported in seven patients $[8,9,17,19$, $22,23,56]$. Progression of disease was reported in seven patients $[15,38,53,64,65,70]$.

\section{Discussion}

Checkpoint immunotherapy has revolutionized the treatment options in oncology. ICI-induced myocarditis is a rare, but serious, and often fatal adverse event. To our knowledge, this is the largest review of 87 cases of ICI-induced myocarditis treated by corticosteroids alone or immunosuppressive therapy other than corticosteroids, where various immunosuppressive therapy regimens were used. It is evident that better treatment guidelines are needed when it comes to treatment of ICI-induced myocarditis.

The median time to onset of symptoms after initiation of ICI was 16 days (range, 1-196 days) equivalent to two cycles of ICI (range, 1-13 cycles). Mahmood et al. reported a median time of onset of myocarditis 34 days after first ICI dose [72]. Escudier et al. reported a median time of 65 days from initiation of ICI to presentation of cardiotoxic effects, but also with a wide variation of 2 to 454 days [73]. Hence ICI-myocarditis should still be considered even though the patients have received several cycles of ICI therapy. We observed $48 \%$ with fatal outcome. Other studies have reported a fatality rate of $50 \%$ of myocarditis cases, with fatality being most frequent in ICI combination therapy (65.5\%) [2]. Follow-up in the cases had a wide variation as some cases did not have any follow-up after the patients were discharged and others included a follow-up of several months. This makes it difficult to make an assessment of the long-term effect of the immunosuppressive regimens in some of the cases in regards to the cardiac function.

Myocarditis is an inflammatory disease of the myocardium caused by a broad variety of infectious and autoimmune conditions. Myocarditis is microscopically categorized according to the predominant histopathologic pattern generally reflecting different aetiologies and pathogenic mechanisms, which could impact the choice of treatment. In the fulminant phase of lymphocytic myocarditis, myocyte damage/necrosis is a common histopathologic finding, which is gradually substituted by fibrosis in the healing process [74]. One possible pathophysiologic mechanism of ICI-myocarditis is that cardiac myocytes may share targeted antigens with the tumor, therefore becoming targets of activated T-lymphocytes resulting in lymphocytic infiltration of the myocardium [39]. Myocarditis can cause several cardiovascular complications such as arrhythmias, myocardial infarction, heart failure or cardiogenic shock. Outcome is favorable in half of the patients, but 25\% develop persistent cardiac dysfunction. Myocarditis can also result in sudden cardiac death, fulminant heart failure or progressive dilated cardiomyopathy [75]. Hence immediate initiation of immunosuppressive treatment is vital to avoid irreversible immune-mediated damage to the heart. An important biopsy finding in our study was that the pathological finding of ICI-induced myocarditis is identical to lymphocytic myocarditis in general. Twenty of the reported cases contained endomyocardial biopsies, showing lymphocytic infiltration within the myocardium primarily comprising T-lymphocytes; consistent with our findings and with the diagnosis lymphocytic myocarditis. A study by Escudier et al. reported lymphocytic myocarditis on biopsies in 8 out of 9 patients [73]. Immunosuppressive agents that target T-lymphocytes could therefore be a suitable therapy for ICI-induced myocarditis based on the histopathologic pattern of lymphocytic myocarditis and from an immunologic point of view. Hence, highdose corticosteroids may be first line therapy for ICIinduced myocarditis and should be initiated promptly, and if there is no rapid effect of steroid treatment after a few days, other immunosuppressive agents should be promptly added in order to minimize immune-mediated destruction of the myocardium and subsequent damage to the heart. We observed a lower fatality in cases treated with immunosuppressive agents other than steroid compared to cases treated with steroid only ( 43 vs. $55 \%$ ), which suggests that outcome improves by adding other immunosuppressive agents, when steroid treatment alone has insufficient clinical effect. However, the overall observed fatality of the cases was high (48\%), which could indicate that immunosuppressive treatment in general was not initiated rapidly enough; a better outcome would probably have been reported if immunosuppressive treatment were initiated faster. Future research may clarify whether non-steroids may be initiated initially, omitting steroids.

Esfahani et al. reported the first case of treatment with alemtuzumab, a CD52-inhibitor. Treatment led to rapid cytolytic immunosuppression with resolution of cardiac immune toxic effects and sustained complete tumor response at 4-month follow-up [8]. Thus, using alemtuzumab as a second line treatment may be an option due to its ability to rapidly deplete T-lymphocytes from the circulation and hence minimize autoimmune damage to the myocardium. However, so far treatment with alemtuzumab has only been reported in one case. Further research is warranted.

Two cases of treatment with abatacept were reported by Salem et al. and Liu et al. [9, 17]. In the case by Salem et al. treatment with abatacept led to rapid decrease in troponin levels and symptoms with persisting tumor control after one month of administration of abatacept [9]. In the case by Liu et al. abatacept treatment improved the patient's functional status, however troponin levels were 
persistently elevated despite 6.5 months of immunosuppressive treatment. Surveillance CT showed tumor control [17]. These findings could suggest that treatment with alemtuzumab or abatacept as second line therapy could be effective in treating ICI-induced myocarditis as both substances target T-lymphocytes, which are the predominant finding in endomyocardial biopsies from patients with ICI-induced myocarditis, as reported in both this and previous studies $[11,16,19,22,23,26,36-39,42,43$, $47,50,61,62,67,71]$. Furthermore treating ICI-induced myocarditis with alemtuzumab or abatacept could have a positive outcome in regard to tumor control compared to other immunosuppressive agents. On the contrary, treating ICI-induced myocarditis with infliximab (monoclonal antibody that inhibits tumor necrosis factor alpha) increases the risk of death from cardiovascular causes with odds ratio 12.0 , as was reported in a recent study by Cautela et al. [76]. We also observed that in cases treated with infliximab 3 out of 8 patients (37.5\%) died of cardiovascular causes $[39,47,50]$. Thus, protecting the heart, but not losing the value of the immunotherapy on the cancer, is the optimal balance; that was demonstrated sadly in our patient, that only received high-dose corticosteroid treatment.

Treatment with alemtuzumab and abatacept can both give rise to infections and there is a risk of inducing autoimmune diseases when treating with alemtuzumab. However, these adverse events do not especially differ from adverse events induced by other immunosuppressive agents. Another advantage of immunosuppressive treatment with alemtuzumab or abatacept is that it would be possible to reduce steroid-doses, as prolonged highdose steroid treatment can be toxic. Prospective studies evaluating the most efficient treatment are warranted.

All myocarditis CTCAE grades warrant work-up and intervention given potential for cardiac compromise. The current ASCO guideline [3] recommend that patients treated with ICIs are monitored with biochemical markers (cardiac biomarkers) and ECG at baseline. If these are abnormal or the patients become

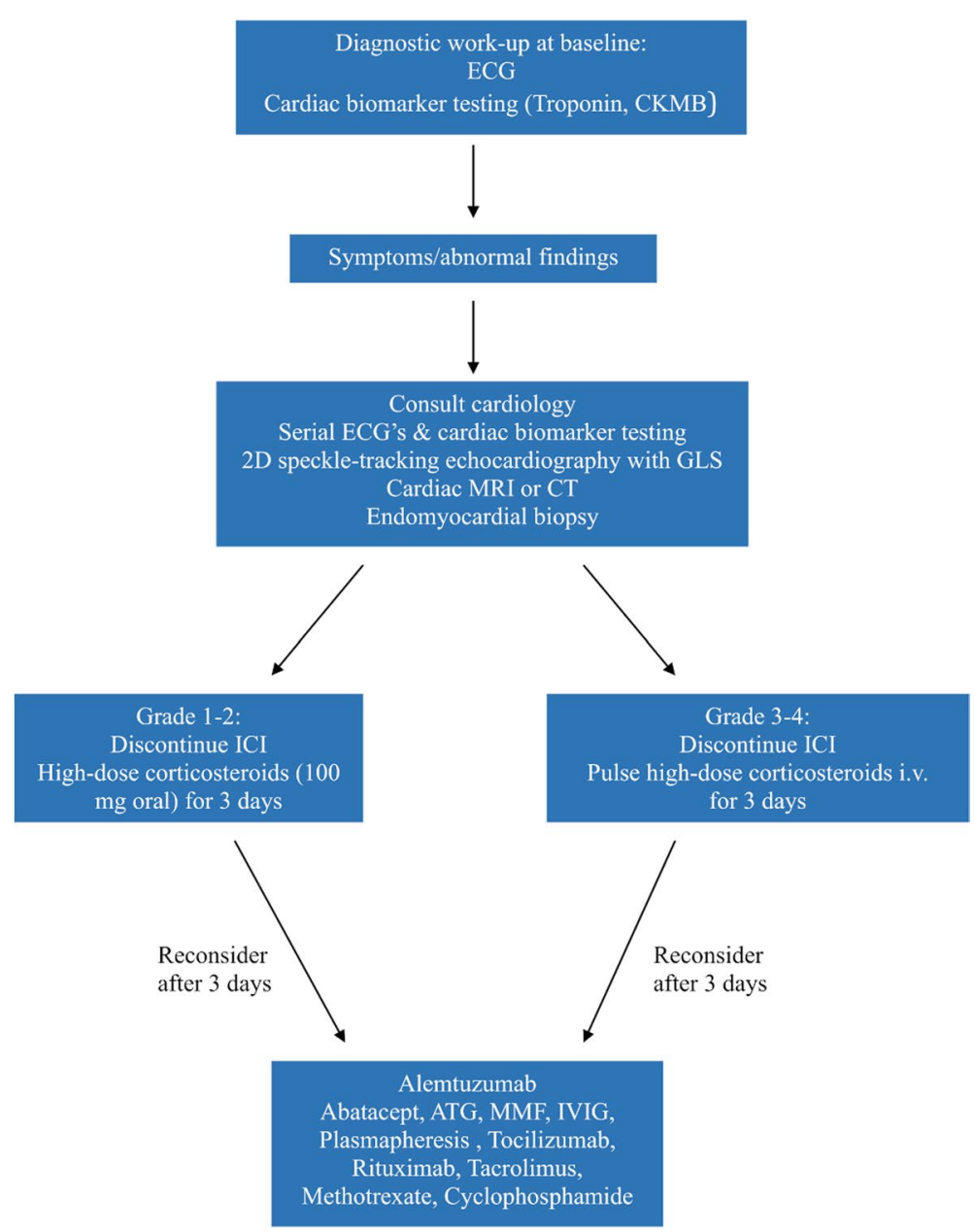

Fig. 4 Assessment and management guideline for $\mathrm{ICl}$ induced myocarditis 
symptomatic, cardiology consultation should be pursued with serial ECGs and cardiac biomarker testing. 2D speckle-tracking echocardiography with GLS should be performed, as some patients with myocarditis show preserved LVEF. Other diagnostics should include cardiac MRI or CT and endomyocardial biopsy [77]. The endomyocardial biopsy is the gold-standard test for the diagnosis of myocarditis [78, 79]. The clinical mindset should be an aggressive approach to diagnosis with MRI and/or endomyocardial biopsy, and if myocarditis is found, treatment could be initiated immediately, whether or not symptoms are present. Management of CTCAE grade 1 myocarditis (i.e., elevated cardiac biomarkers without symptoms) and CTCAE grade 2 myocarditis (i.e., symptoms with moderate activity), or persistent elevated cardiac biomarkers should include discontinuation of ICI treatment and treatment with oral high-dose corticosteroids ( $100 \mathrm{mg}$ daily) for 3 days; if there is insufficient effect of steroid treatment clinicians should revaluate and consider adding other immunosuppressive agents. For the management of CTCAE grade 3 or 4 myocarditis pulse high-dose corticosteroids IV should be given for 3 days as a first line treatment; if there is clinical improvement consider reducing steroid doses (by $20 \mathrm{mg}$ daily) and follow cardiac markers closely. If there is no clinical improvement after 3 days of high-dose corticosteroid treatment, other immunosuppressive agents should be added. Clinicians could use findings in endomyocardial biopsies to guide supplement immunosuppressive therapy (Fig. 4).

To our knowledge, based on clinicaltrials.gov, there are no on-going clinical trials evaluating treatments for ICI-induced myocarditis. However, the ASCO guideline is based on limited data and will be expected to change as more data are accrued.

This review has limitations mainly due to the reporting of case series only; this has generally the lowest grade of evidence. Moreover, the included information in the case reports varied considerably where only $13 \%$ had low risk of bias, according to the criteria by Murad et al. [6]. None of the included studies reported adverse events to the immunosuppressive therapies, which leaves the reader to wonder if it is possible that no adverse events were reported due to the large amounts of immunosuppressive agents used.

\section{Conclusion}

Immune checkpoint inhibitor induced myocarditis is a serious and often fatal adverse event. High-dose prednisolone, alemtuzumab or abatacept are all possible treatments for ICI-induced myocarditis, whereas infliximab increases the risk of death from cardiovascular causes, and should be avoided. Further research is needed to determine the most effective immunosuppressive therapeutic strategy for ICI-induced myocarditis.

\section{Acknowledgements}

Not applicable

\section{Authors' contributions}

E.M. contributed to concept and design, data analysis and drafted the first manuscript version. L.E.B. contributed to data analysis and manuscript editing. B.L., S.H. and C.S. contributed to provision of study material, data analysis and manuscript editing. F.D. contributed to concept and design, provision of study material, data analysis and manuscript editing. All authors agreed to submission and to be accountable of all aspects of the work.

\section{Funding}

F.D. received research grant from the Health Research Fund Central Denmark Region.

\section{Availability of data and materials}

The datasets used and/or analyzed during the current study are available from the corresponding author on reasonable request.

\section{Declarations}

\section{Ethics approval and consent to participate}

Ethical permits for this study were obtained from The Danish Patient Safety Authority (31-1521-314) and the Danish Data Protection Agency (1-16-02-236-20)

\section{Consent for publication}

The data is presented so that no individual study participants can be identified.

\section{Competing interests}

FD reported grants from Pfizer, MSD and Ipsen.E.M., L.E.B., B.L., S.H. and C.S. declare no conflict of interests.

\section{Author details}

'Department of Oncology, Aarhus University Hospital, Palle Juul-Jensens, Boulevard 99, 8200 Aarhus N, Denmark. ²Department of Rheumatology, Aarhus University Hospital, Aarhus, Denmark. ${ }^{3}$ Department of Cardiology, Aarhus University Hospital, Aarhus, Denmark. ${ }^{4}$ Department of Pathology, Aarhus University Hospital, Aarhus, Denmark.

Received: 5 March 2021 Accepted: 16 July 2021

Published online: 09 August 2021

\section{References}

1. Hargadon KM, Johnson CE, Williams CJ. Immune checkpoint blockade therapy for cancer: an overview of FDA-approved immune checkpoint inhibitors. Int Immunopharmacol. 2018;62:29-39.

2. Salem JE, Manouchehri A, Moey M, Lebrun-Vignes B, Bastarache L, Pariente A, et al. Cardiovascular toxicities associated with immune checkpoint inhibitors: an observational, retrospective, pharmacovigilance study. Lancet Oncol. 2018;19(12):1579-89.

3. Brahmer JR, Lacchetti C, Schneider BJ, Atkins MB, Brassil KJ, Caterino $J M$, et al. Management of immune-related adverse events in patients treated with immune checkpoint inhibitor therapy: american society of clinical oncology clinical practice guideline. J Clin Oncol. 2018;36(17):1714-68.

4. Ponikowski P, Voors AA, Anker SD, Bueno H, Cleland JG, Coats AJ, et al. 2016 ESC Guidelines for the diagnosis and treatment of acute and chronic heart failure: The Task Force for the diagnosis and treatment of acute and chronic heart failure of the European Society of Cardiology (ESC). Developed with the special contribution of the Heart Failure Association (HFA) of the ESC. Eur J Heart Fail. 2016;18(8):891-975. 
5. Heng DY, Xie W, Regan MM, Warren MA, Golshayan AR, Sahi C, et al. Prognostic factors for overall survival in patients with metastatic renal cell carcinoma treated with vascular endothelial growth factortargeted agents: results from a large, multicenter study. J Clin Oncol. 2009;27(34):5794-9.

6. Murad MH, Sultan S, Haffar S, Bazerbachi F. Methodological quality and synthesis of case series and case reports. BMJ Evid Based Med. 2018;23(2):60-3.

7. Doms J, Prior JO, Peters S, Obeid M. Tocilizumab for refractory severe immune checkpoint inhibitor-associated myocarditis. Ann Oncol. 2020;31(9):1273-5.

8. Esfahani K, Buhlaiga N, Thébault P, Lapointe R, Johnson NA, Miller WH Jr. Alemtuzumab for immune-related myocarditis due to PD-1 therapy. N Engl J Med. 2019;380(24):2375-6.

9. Salem J-E, Allenbach Y, Vozy A, Brechot N, Johnson DB, Moslehi JJ, et al. Abatacept for severe immune checkpoint inhibitor-associated myocarditis. N Engl J Med. 2019;380(24):2377-9.

10. Matzen E, Bartels LE, Løgstrup B, Horskær S, Stilling C, Donskov F. Immune checkpoint inhibitor-induced myocarditis in cancer patients: a case report and review of reported cases. Cardio Oncol. 2021. https://doi.org/ 10.1186/s40959-021-00114-x.

11. Läubli H, Balmelli C, Bossard M, Pfister O, Glatz K, Zippelius A. Acute heart failure due to autoimmune myocarditis under pembrolizumab treatment for metastatic melanoma. J Immunother Cancer. 2015;3:11.

12. Zimmer L, Goldinger SM, Hofmann L, Loquai C, Ugurel S, Thomas I, et al. Neurological, respiratory, musculoskeletal, cardiac and ocular side-effects of anti-PD-1 therapy. Eur J Cancer. 2016;60:210-25.

13. Behling J, Kaes J, Münzel T, Grabbe S, Loquai C. New-onset third-degree atrioventricular block because of autoimmune-induced myositis under treatment with anti-programmed cell death-1 (nivolumab) for metastatic melanoma. Melanoma Res. 2017;27(2):155-8.

14. Semper H, Muehlberg F, Schulz-Menger J, Allewelt M, Grohé C. Druginduced myocarditis after nivolumab treatment in a patient with PDL1- negative squamous cell carcinoma of the lung. Lung Cancer. 2016;99:117-9.

15. Mahmood SS, Chen CL, Shapnik N, Krishnan U, Singh HS, Makker V. Myocarditis with tremelimumab plus durvalumab combination therapy for endometrial cancer: a case report. Gynecol Oncol Rep. 2018;25:74-7.

16. Jain V, Mohebtash M, Rodrigo ME, Ruiz G, Atkins MB, Barac A. Autoimmune myocarditis caused by immune checkpoint inhibitors treated with antithymocyte globulin. J Immunother. 2018;41(7):332-5.

17. Liu S, Chan J, Brinc D, Gandhi S, Izenberg A, Delgado D, Abdel-Qadir H, Wintersperger BJ, Thavendiranathan P. Immune checkpoint inhibitorassociated myocarditis with persistent troponin elevation despite abatacept and prolonged immunosuppression. JACC: CardioOncol. 2020;2(5):800-4.

18. Frigeri M, Meyer P, Banfi C, Giraud R, Hachulla AL, Spoerl D, et al. Immune checkpoint inhibitor-associated myocarditis: a new challenge for cardiologists. Can J Cardiol. 2018;34(1):92.e1-92.e3.

19. Norwood TG, Westbrook BC, Johnson DB, Litovsky SH, Terry NL, MCKee SB, et al. Smoldering myocarditis following immune checkpoint blockade. J Immunother Cancer. 2017;5(1):91.

20. Arangalage D, Delyon J, Lermuzeaux M, Ekpe K, Ederhy S, Pages C, et al. Survival after fulminant myocarditis induced by immune-checkpoint inhibitors. Ann Intern Med. 2017;167(9):683-4.

21. Yogasundaram H, Alhumaid W, Chen JW, Church M, Alhulaimi N, Kimber S, Paterson DI, Senaratne JM. Plasma exchange for immune checkpoint inhibitor-induced myocarditis. CJC Open. 2020;3(3):379-82.

22. Tay RY, Blackley E, McLean C, Moore M, Bergin P, Gill S, et al. Successful use of equine anti-thymocyte globulin (ATGAM) for fulminant myocarditis secondary to nivolumab therapy. Br J Cancer. 2017;117(7):921-4.

23. Tadokoro T, Keshino E, Makiyama A, Sasaguri T, Ohshima K, Katano H, et al. Acute lymphocytic myocarditis with anti-PD-1 antibody nivolumab. Circulation Heart Failure. 2016;9(10):e003514

24. Gibson R, Delaune J, Szady A, Markham M. Suspected autoimmune myocarditis and cardiac conduction abnormalities with nivolumab therapy for non-small cell lung cancer. BMJ Case Rep. 2016;2016:bcr2016216228.

25. Guiney TE, Lopes MS, Kalra MK, Mooradian MJ, Neilan TG, Stone JR. Case 30-2019: a 65-year-old woman with lung cancer and chest pain. N Engl J Med. 2019;381(13):1268-77.
26. Itzhaki Ben Zadok O, Ben-Avraham B, Nohria A, Orvin K, Nassar M, lakobishvili Z, Neiman V, Goldvaser H, Kornowski R, Ben Gal T. Immunecheckpoint inhibitor-induced fulminant myocarditis and cardiogenic shock. JACC: CardioOncol. 2019;1 (1):141-4.

27. Mehta A, Gupta A, Hannallah F, Koshy T, Reimold S. Myocarditis as an immune-related adverse event with ipilimumab/nivolumab combination therapy for metastatic melanoma. Melanoma Res. 2016;26(3):319-20.

28. Reuben A, Petaccia de Macedo M, McQuade J, Joon A, Ren Z, Calderone T, et al. Comparative immunologic characterization of autoimmune giant cell myocarditis with ipilimumab. Oncoimmunology. 2017;6(12):e1361097.

29. Tajmir-Riahi A, Bergmann T, Schmid M, Agaimy A, Schuler G, Heinzerling L. Life-threatening autoimmune cardiomyopathy reproducibly induced in a patient by checkpoint inhibitor therapy. J Immunother. 2018;41 (1):35-8.

30. Berg DD, Vaduganathan M, Nohria A, Davids MS, Alyea EP, Torre M, et al. Immune-related fulminant myocarditis in a patient receiving ipilimumab therapy for relapsed chronic myelomonocytic leukaemia. Eur J Heart Fail. 2017;19(5):682-5.

31. Samara Y, Yu CL, Dasanu CA. Acute autoimmune myocarditis and hepatitis due to ipilimumab monotherapy for malignant melanoma. J Oncol Pharm Pract. 2019;25(4):966-8.

32. Khoury ZH, Hausner PF, Idzik-Starr CL, Frykenberg MRA, Brooks JK, Dyalram D, et al. Combination nivolumab/ipilimumab immunotherapy for melanoma with subsequent unexpected cardiac arrest: a case report and review of literature. J Immunother. 2019;42(8):313-7.

33. Katsume Y, Isawa T, Toi Y, Fukuda R, Kondo Y, Sugawara S, et al. Complete atrioventricular block associated with pembrolizumab-induced acute myocarditis: the need for close cardiac monitoring. Intern Med. 2018;57(21):3157-62.

34. Yanase T, Moritoki Y, Kondo H, Ueyama D, Akita H, Yasui T. Myocarditis and myasthenia gravis by combined nivolumab and ipilimumab immunotherapy for renal cell carcinoma: a case report of successful management. Urol Case Rep. 2021;34:101508.

35. Reddy N, Moudgil R, Lopez-Mattei JC, Karimzad K, Mouhayar EN, Somaiah $\mathrm{N}$, et al. Progressive and reversible conduction disease with checkpoint inhibitors. Can J Cardiol. 2017;33(10):1335.e13-1335.e15.

36. Ganatra S, Neilan TG. Immune checkpoint inhibitor-associated myocarditis. Oncologist. 2018;23(8):879-86.

37. Fukasawa Y, Sasaki K, Natsume M, Nakashima M, Ota S, Watanabe K, et al. Nivolumab-induced myocarditis concomitant with myasthenia gravis. Case Rep Oncol. 2017;10(3):809-12.

38. Imai R, Ono M, Nishimura N, Suzuki K, Komiyama N, Tamura T. Fulminant myocarditis caused by an immune checkpoint inhibitor: a case report with pathologic findings. J Thorac Oncol. 2019;14(2):e36-8.

39. Johnson DB, Balko JM, Compton ML, Chalkias S, Gorham J, Xu Y, et al. Fulminant myocarditis with combination immune checkpoint blockade. N Engl J Med. 2016;375(18):1749-55.

40. Nasr F, El Rassy E, Maalouf G, Azar C, Haddad F, Helou J, et al. Severe ophthalmoplegia and myocarditis following the administration of pembrolizumab. Eur J Cancer. 2018;91:171-3.

41. Rota E, Varese P, Agosti S, Celli L, Ghiglione E, Pappalardo I, et al. Concomitant myasthenia gravis, myositis, myocarditis and polyneuropathy, induced by immune-checkpoint inhibitors: a life-threatening continuum of neuromuscular and cardiac toxicity. eNeurologicalsci. 2019;14:4-5.

42. Yamaguchi $\mathrm{S}$, Morimoto R, Okumura T, Yamashita Y, Haga T, Kuwayama T, et al. Late-onset fulminant myocarditis with immune checkpoint inhibitor nivolumab. Can J Cardiol. 2018;34(6):812.e1-812.e3.

43. Chen Q, Huang DS, Zhang LW, Li YQ, Wang HW, Liu HB. Fatal myocarditis and rhabdomyolysis induced by nivolumab during the treatment of type B3 thymoma. Clin Toxicol (Phila). 2018;56(7):667-71.

44. Nierstedt RT, Yeahia R, Barnett KM. Unanticipated myocarditis in a surgical patient treated with pembrolizumab: a case report. A\&A Pract. 2020;14(6):e01177.

45. Cristina AA, Escudier-Villa JM, Marcos JO, Silva-Melchor L. Progressive exertional dyspnea and fatigue in an oncol-ogy-patient. Austin J Clin Cardiol. 2017:4(2):1058.

46. Copeland-Halperin R, Goldman M, Sahni G. Autoimmune myocarditis with AV block: too much of a good thing?: American College of Cardiology; 2018. https://www.acc.org/education-and-meetings/patie 
nt-case-quizzes/2018/05/29/06/46/autoimmune-myocarditis-with-avblock. Accessed 29 Jan 2021.

47. Gallegos C, Rottmann D, Nguyen VQ, Baldassarre LA. Myocarditis with checkpoint inhibitor immunotherapy: case report of late gadolinium enhancement on cardiac magnetic resonance with pathology correlate. Eur Heart J Case Rep. 2019;3(1):yty149.

48. Inayat F, Masab M, Gupta S, Ullah W. New drugs and new toxicities: pembrolizumab-induced myocarditis. BMJ Case Rep. 2018:2018:bcr-2017-223252.

49. Lopez EMDS, Mazimba S. Malignant arrhythmias in autoimmune myocarditis secondary to immune checkpoint blockade treatment. J Am College Cardiol. 2018;71:A2375.

50. Martinez-Calle N, Rodriguez-Otero P, Villar S, Mejías L, Melero I, Prosper $F$, et al. Anti-PD1 associated fulminant myocarditis after a single pembrolizumab dose: the role of occult pre-existing autoimmunity. Haematologica. 2018;103(7):e318-21.

51. Monge C, Maeng H, Brofferio A, Apolo AB, Sathya B, Arai AE, et al. Myocarditis in a patient treated with Nivolumab and PROSTVAC: a case report. J Immunother Cancer. 2018;6(1):150.

52. Sakai T, Sasada S, Jyo C, Ishioka K, Takahashi S, Nakamura M. Acute myocarditis and pericarditis after nivolumab treatment in patients with non-small cell lung cancer. Ann Oncol. 2017;28:mdx697.072.

53. Balanescu DV, Donisan T, Palaskas N, Lopez-Mattei J, Kim PY, Buja LM, et al. Immunomodulatory treatment of immune checkpoint inhibitor-induced myocarditis: Pathway toward precision-based therapy. Cardiovasc Pathol. 2020:47:107211.

54. Guo CW, Alexander M, Dib Y, Lau PKH, Weppler AM, Au-Yeung G, et al. A closer look at immune-mediated myocarditis in the era of combined checkpoint blockade and targeted therapies. Eur J Cancer. 2020;124:15-24.

55. Bukamur HS, Mezughi H, Karem E, Shahoub I, Shweihat Y. Nivolumabinduced third degree atrioventricular block in a patient with stage IV squamous cell lung carcinoma. Cureus. 2019;11(6):e4869.

56. Agrawal N, Khunger A, Vachhani P, Colvin TA, Hattoum A, Spangenthal E, et al. Cardiac toxicity associated with immune checkpoint inhibitors: case series and review of the literature. Case Rep Oncol. 2019;12(1):260-76.

57. Arora P, Talamo L, Dillon P, Gentzler RD, Millard T, Salerno M, et al. Severe combined cardiac and neuromuscular toxicity from immune checkpoint blockade: an institutional case series. Cardio Oncol. 2020;6:21.

58. Xing Q, Zhang ZW, Lin QH, Shen LH, Wang PM, Zhang S, et al. Myositismyasthenia gravis overlap syndrome complicated with myasthenia crisis and myocarditis associated with anti-programmed cell death-1 (sintilimab) therapy for lung adenocarcinoma. Ann Transl Med. 2020;8(5):250.

59. Kimura T, Fukushima S, Miyashita A, Aoi J, Jinnin M, Kosaka T, et al. Myasthenic crisis and polymyositis induced by one dose of nivolumab. Cancer Sci. 2016;107(7):1055-8.

60. Fazel M, Jedlowski PM. Severe myositis, myocarditis, and myasthenia gravis with elevated anti-striated muscle antibody following single dose of ipilimumab-nivolumab therapy in a patient with metastatic melanoma. Case Rep Immunol. 2019;2019:2539493.

61. Hardy T, Yin M, Chavez JA, Ivanov I, Chen W, Nadasdy T, et al. Acute fatal myocarditis after a single dose of anti-PD-1 immunotherapy, autopsy findings: a case report. Cardiovasc Pathol. 2020:46:107202.

62. Saibil SD, Bonilla L, Majeed H, Sotov V, Hogg D, Chappell MA, et al. Fatal myocarditis and rhabdomyositis in a patient with stage IV melanoma treated with combined ipilimumab and nivolumab. Curr Oncol. 2019:26(3):e418-21.

63. Ansari-Gilani K, Tirumani SH, Smith DA, Nelson A, Alahmadi A, Hoimes CJ, et al. Myocarditis associated with immune checkpoint inhibitor therapy: a case report of three patients. Emerg Radiol. 2020;27(4):455-60.
64. McDowall LM, Fernando SL, Ange N, Yun J, Chia KKM. Immune checkpoint inhibitor-mediated myocarditis and ventricular tachycardia storm HeartRhythm Case Rep. 2019;5(10):497-500.

65. Shah M, Tayar JH, Abdel-Wahab N, Suarez-Almazor ME. Myositis as an adverse event of immune checkpoint blockade for cancer therapy. Semin Arthritis Rheum. 2019;48(4):736-40.

66. Joseph A, Simonaggio A, Stoclin A, Vieillard-Baron A, Geri G, Oudard S, et al. Immune-related adverse events: a retrospective look into the future of oncology in the intensive care unit. Ann Intensive Care. 2020;10(1):143.

67. Zhang L, Jones-O'Connor M, Awadalla M, Zlotoff DA, Thavendiranathan P, Groarke JD, et al. Cardiotoxicity of immune checkpoint inhibitors. Curr Treat Options Cardiovasc Med. 2019;21(7):32.

68. Konstantina T, Konstantinos R, Anastasios K, Anastasia M, Eleni L, loannis $\mathrm{S}$, et al. Fatal adverse events in two thymoma patients treated with antiPD-1 immune check point inhibitor and literature review. Lung Cancer. 2019;135:29-32.

69. Wang H, Tian R, Gao P, Wang Q, Zhang L. Tocilizumab for fulminant programmed death 1 inhibitor-associated myocarditis. J Thorac Oncol. 2020;15(3):e31-2.

70. von Itzstein MS, Khan S, Popat V, Lu R, Khan SA, Fattah FJ, et al. Statin intolerance, anti-HMGCR antibodies, and immune checkpoint inhibitor-associated myositis: a "two-hit" autoimmune toxicity or clinical predisposition? Oncologist. 2020;25(8):e1242-5.

71. Heinzerling L, Ott PA, Hodi FS, Husain AN, Tajmir-Riahi A, Tawbi H, et al. Cardiotoxicity associated with CTLA4 and PD1 blocking immunotherapy. J Immunother Cancer. 2016;4:50.

72. Mahmood SS, Fradley MG, Cohen JV, Nohria A, Reynolds KL, Heinzerling $L M$, et al. Myocarditis in patients treated with immune checkpoint inhibitors. J Am Coll Cardiol. 2018;71(16):1755-64.

73. Escudier M, Cautela J, Malissen N, Ancedy Y, Orabona M, Pinto J, et al. Clinical features, management, and outcomes of immune checkpoint inhibitor-related cardiotoxicity. Circulation. 2017;136(21):2085-7.

74. Leone O, Pieroni M, Rapezzi C, Olivotto I. The spectrum of myocarditis: from pathology to the clinics. Virchows Archiv. 2019;475(3):279-301.

75. Caforio AL, Pankuweit S, Arbustini E, Basso C, Gimeno-Blanes J, Felix SB, et al. Current state of knowledge on aetiology, diagnosis, management, and therapy of myocarditis: a position statement of the European Society of Cardiology Working Group on Myocardial and Pericardial Diseases. Eur Heart J. 2013;34(33):2636-48 (48a-48d).

76. Cautela J, Zeriouh S, Gaubert M, Bonello L, Laine M, Peyrol M, et al. Intensified immunosuppressive therapy in patients with immune checkpoint inhibitor-induced myocarditis. J Immunother Cancer. 2020;8(2):e001887.

77. Bonaca MP, Olenchock BA, Salem JE, Wiviott SD, Ederhy S, Cohen A, et al. Myocarditis in the setting of cancer therapeutics: proposed case definitions for emerging clinical syndromes in cardio-oncology. Circulation. 2019;140(2):80-91.

78. Leone OVJ, Angelini A, Baandrup UT, Basso C, Berry G, et al. 2011 consensus statement on endomyocardial biopsy from the Association for European Cardiovascular Pathology and the Society for Cardiovascular Pathology. Cardiovasc Pathol. 2012;21(4):245-74.

79. Ferreira VM, Schulz-Menger J, Holmvang G, Kramer CM, Carbone I, Sechtem U, et al. Cardiovascular magnetic resonance in nonischemic myocardial inflammation: expert recommendations. J Am Coll Cardiol. 2018;72(24):3158-76.

\section{Publisher's Note}

Springer Nature remains neutral with regard to jurisdictional claims in published maps and institutional affiliations. 